\title{
ON THE ROLE OF ESSENTIAL ORDERS ON FEEDBACK DECOUPLING AND MODEL INVERSION: BOND GRAPH APPROACH
}

\author{
Mariem El Feki, Michael Di Loreto, Eric Bideaux, Daniel Thomasset, Wilfrid Marquis-Favre \\ Laboratoire Ampère (UMR 5005), INSA Lyon, France \\ Bât. St Exupéry \\ 25, Avenue Jean capelle, Villeurbanne, 69621 \\ E-mail: mariem.el-feki@ec-lyon.fr
}

\section{KEYWORDS}

Bond Graph, structure analysis, essential order, inverse model, decoupling, dynamic extension

\begin{abstract}
The essential orders have an important role in the study of the systems decouplability as well as in the inverse model characterization. The aim of this paper is first to define essential orders on the bond graph model. Secondly, static and dynamic decoupling by bond graph approach is discussed and the dynamic extension order is defined. Finally, the dynamic compensation is physically located on the bond graph model and an approach to synthesize a model statically decouplable is suggested in order to define an adequate structure to the control requirements.
\end{abstract}

\section{INTRODUCTION}

Since its apparition the bond graph has been an efficient graphic support modelling for complex and multidisciplinary systems (Rosenberg et al. 1996; Karnopp et al. 2000; Gawthrop and Bevan 2007). However, modelling is not the only contribution of Bond graphs. Several works were achieved to develop system analysis using causal bond graphs, like stability analysis (Margolis 1984) or flatness study (Junco et al. 2005). The structure analysis by bond graph approach of linear time-invariant systems was introduced by (Rahmani et al. 1996; Dauphin-Tanguy, et al., 1999; Karim et al. 2003) to simplify decouplability study of these systems and without making any calculation. So, static decoupling conditions were defined on the bond graph model. The structural properties were generally used to the control problems (Loiseau 1986). Nevertheless some structural properties like essential orders (Commault et al 1986) have a very important significance when studying inverse model and consequently when modelling the systems to be controlled.

The purpose of this paper is to expand structure analysis by bond graph approach to define essential orders in order to interpret these orders on the inverse model and to discuss the system decouplability and the dynamic compensation if the system is invertible but not decouplable by static feedback.
In a first section, we recall preliminary results on the power lines, causal paths and model inversion. In second part, brief results on the infinite structure analysis are given and the extension of this analysis by bond graph approach is presented. In the next section, decoupling conditions are defined. Then, an approach to synthesize a model statically decouplable is discussed on the bond graph model. A mechanical example is established and treated in the different sections of the paper. The conclusion is given in the last section.

\section{MODEL INVERSION: PRELIMINARY RESULTS}

The inversion of bond graph model uses the bicausality concept which was introduced formally by Gawthrop (Gawthrop 1995 and 1997). This concept established new rules for causal assignment and it has contributed at the study of inverse problems (Gawthrop 2000; Ngwompo et al. 2005; Bideaux et al. 2006) and at design and sizing problems (Ngwompo et al. 1999 and 2001). The bicausality propagation is done according to SCAPI procedure (Ngwompo et al. 2005). This procedure uses the concept of independent power lines and disjoint Input-Output (I/O) causal paths.

Definition1 (Wu and Youcef-Toumi 1995)

A power line between two components is a series of power bonds and junction structure elements connecting these two components.

Definition2 (Ngwompo et al. 2001)

A causal path between two variables is a set of variables successively connected according to the causality assignment.

Definition3 (Sueur and Dauphin-Tanguy 1989; Sueur and Dauphin-Tanguy 1991)

An I/O causal path $\left(u_{j}, y_{i}\right)$ is a path starting from a modulated command element $\left(\mathrm{MS}_{\mathrm{e}}, \mathrm{MS}_{\mathrm{f}}, \mathrm{MR}, ..\right)$ and going to a detector $y_{i}\left(D_{e}\right.$ or $\left.D_{f}\right)$. Note that the power lines are an acausal concept while causal paths are defined for causal bond graphs.

Definition4 (Ngwompo et al. 2005)

Two I/O power lines are independent if they do not share a common variable: no effort or flow variable in common. 
Definition5 (Ngwompo 1997)

Two I/O causal paths are said to be disjoint if they have no variable in common. Thus, "independent" is a property of power lines while "disjoint" is a property of causal paths.

Definition6 (Rahmani et al. 1992).

The length of a causal path between an output $y_{i}$ and an input $u_{j}$ is equal to the number of dynamic elements in integral causality met along this path in the bond graph in preferential integral causality (BGI).

The system is not structurally invertible if the bond graph model contains no set of independent I/O power lines. If the bond graph model contains a unique set of independent $\mathrm{I} / \mathrm{O}$ power lines then a necessary and not sufficient condition of the structurally invertibility is verified (Ngwompo et al. 2005). If the bond graph model contains multiple sets of independent I/O power lines, then the necessary condition of the structurally invertibility consists of finding a minimal-length set of disjoint I/O causal paths. If a non-solvable causal cycle appears after the propagation of the $\mathrm{O} / \mathrm{I}$ bicausality along the minimal length set of I/O causal paths, then it must choose an alternative minimal- length or a longer set of I/O causal paths and the bicausality propagation repeated. If a non-solvable causal cycle remains in the model then we can not conclude on the system invertibility. (Ngwompo et al. 2001). In this case, a modification of the system structure can be an adequate solution to synthesize a system with a bond graph model verifying the invertibility condition (For example, adding an action chain). Otherwise, by applying the SCAP (Karnopp et al, 1990) or eventually the MSCAP (Van Dijk, 1990), the causality assignment must be completed to the remaining acausal part of the bicausal bond graph model.

\section{INFINITE STRUCTURE ANALYSIS}

In this part, we recall some results on infinite structure analysis. From some works done on structural analysis by bond graph approach, we define the essential orders on bond graph model.

Let us consider the square linear time-invariant system described by state equations (1).

$$
\left\{\begin{array}{l}
\dot{x}=A x+B u \\
y=C x
\end{array}\right.
$$

With $x \in R^{n}$ denotes the state vector, $u \in R^{p}$ denotes the control vector, and $y \in R^{p}$ denotes the output vector. The relative degree of the $\mathrm{i}^{\text {th }}$ output is defined by:

$$
n_{i}^{\prime}=\inf \left\{\mathrm{k} \in \mathrm{N} / \mathrm{c}_{\mathrm{i}} \mathrm{A}^{\mathrm{k}-1} \mathrm{~B} \neq 0, \mathrm{k}=1, \ldots, \mathrm{n}\right\}
$$

where $c_{i}$ is the $i^{\text {th }}$ row of $\mathrm{C}$.
The relative degree $n_{i}^{\prime}$ is equal, on a bond graph model, to the length $l_{i}$ of the shortest causal path between the $\mathrm{i}^{\text {th }}$ output $\left(\mathrm{D}_{\mathrm{e}}\right.$ or $\left.\mathrm{D}_{\mathrm{f}}\right)$ and all the inputs $\left(\mathrm{S}_{\mathrm{e}}\right.$ or $\left.\mathrm{S}_{\mathrm{f}}\right)$ (Rahmani et al. 1996). The order $n_{i}^{\prime}$ represents the minimal and necessary number of derivations of this output to make appear explicitly at least in one of the inputs, see (Bertrand et al. 1997; Dauphin-Tanguy et al. 2000).

Let us suppose that the system (1) is invertible with a transfer matrix $T(s)$ strictly proper, of rank $p$ and defined by:

$$
T(s)=C(s I-A)^{-1} B
$$

The Smith-McMillan form at infinity of $T(s)$ permits the determination of the infinite zero orders, it is given by:

$$
T(s)=B_{1}(s) \Lambda(s) B_{2}(s)
$$

Where $B_{1}(s)$ and $B_{2}(s)$ are biproper (proper with proper inverse): $\operatorname{det}\left(\lim _{s \rightarrow \infty} B_{i}(s)\right) \neq 0 \quad, \quad \mathrm{i}=1,2 \quad$ and $\Lambda=\operatorname{diag}\left(s^{-n_{1}}, \ldots, s^{-n_{p}}\right)$. Thus, the transfer matrix $T(s)$ has only zeros whose orders are $n_{1}, \ldots, n_{p}$.

On the bond graph model, the number of the infinite zeros of $(\mathrm{A}, \mathrm{B}, \mathrm{C})$ is equal to the number of disjoint $\mathrm{I} / \mathrm{O}$ causal paths and their orders are computed as in equation (5), where $L_{k}$ is the lowest sum of the lengths of the $k \mathrm{I} / \mathrm{O}$ disjoint causal paths (Dauphin-Tanguy, et al., 1999 and 2000).

$$
\left\{\begin{array}{l}
n_{1}=L_{1} \\
\vdots \\
n_{p}=L_{p}-L_{p-1}
\end{array}\right.
$$

Thus, the following property is deduced:

$$
L_{p}=\sum_{i=1}^{p} n_{i}
$$

The essential orders $n_{i e}$ were defined by (Commault et al. 1986) for solving row by row decoupling problems. They are determined from the Toeplitz matrices $\Gamma_{\mu}$ (for $\mu \geq 1$ ) defined by:

$$
\Gamma_{\mu}=\left[\begin{array}{ccccc}
C B & 0 & 0 & \cdots & 0 \\
C A B & C B & 0 & & 0 \\
\vdots & & & \ddots & \vdots \\
\vdots & & & & 0 \\
C A^{\mu-1} B & \cdots & \cdots & C A B & C B
\end{array}\right]
$$


Let us recall that a row $\mathrm{w}_{\mathrm{i}}$ of a given matrix $\mathrm{W}$ is said to be essential if it is not linearly dependent of other rows of W (Cremer 1971).

For a right-invertible system (A, B, C), with $n_{\text {sup }}$ its supremal order of infinite zeros $\left(n_{\text {sup }}=\sup \left\{n_{i}\right\}, i=1, \ldots, p\right)$, the essential order of the $i^{\text {th }}$ output is defined by (Commault et al. 1986):

$$
\begin{gathered}
n_{i e}=\inf \left\{\mathrm{k} \in \mathrm{N} /\left[\mathrm{c}_{\mathrm{i}} \mathrm{A}^{\mathrm{k}-1} \mathrm{~B}|\ldots| \mathrm{c}_{\mathrm{i}} \mathrm{B} \mid 0 \ldots 0\right]\right. \\
\text { is essential in } \left.\Gamma_{n_{\text {sup }}}\right\}
\end{gathered}
$$

Then, the following proprieties are deduced:

(i) $n_{i e} \geq n_{i}^{\prime} \forall \mathrm{i}=1, \ldots, \mathrm{p}$

(ii) $n_{\text {ie }} \leq n_{\text {sup }} \forall \mathrm{i}=1, \ldots, \mathrm{p}$

(iii) $\sup \left\{n_{\text {ie }}\right\}=n_{\text {sup }} \forall \mathrm{i}=1, \ldots, \mathrm{p}$

For any right-invertible system, the essential orders can be expressed as follows (Commault et al. 1986):

$$
n_{i e}=\sum_{j=1}^{p} n_{j}-\sum_{k=1, k \neq i}^{p} n_{k}^{\prime} \quad \forall \mathrm{i} \in\{1, \ldots \mathrm{p}\}
$$

The essential orders have an important signification on the inverse model. Let us recall that the transfer matrix $T(s)$ has only infinite zeros. Thus we can deduce that the transfer matrix of the inverse system $T^{-1}(s)$ has only infinite poles. From this fact, Commault, et al. (1986) showed that the essential order $n_{i e}$ corresponds to the order of the pole at infinity of the $i^{\text {th }}$ column of $T^{-1}(s)$. Thus, we can deduce that the essential order $n_{i e}$ is defined as the highest derivation order of the $i^{\text {th }}$ output appearing in the inverse model

In order to simplify the determination of essential orders, a new method is established to determine these orders directly from the bond graph model and without making any computation.

\section{Property1}

On the bond graph model, the essential order of the $i^{\text {th }}$ output is determined as follows:

$$
n_{i e}=L_{p}-\sum_{j=1, j \neq i}^{p} l_{j} \quad \forall \mathrm{i} \in\{1, \ldots \mathrm{p}\}
$$

On the bicausal bond graph model, the essential order of the $i^{\text {th }}$ output can be determined directly:

$$
n_{i e}=O_{h}\left(O_{i} / I_{j}\right) \quad \forall \mathrm{j} \in\{1, \ldots \mathrm{p}\}
$$

$O_{h}\left(O_{i} / I_{j}\right)$ corresponds to the highest order of the causal paths between the $i^{\text {th }}$ output and all the inputs on the bicausal bond graph. The order of a causal path on bicausal bond graph corresponds to the difference between the number of the dynamic elements (I or C) in derivative causality and the number of the dynamic elements in integral causality met on this path.

The property (10) is a conjectural and enables the essential orders, directly from the bicausal bond graph, to be deduced. Its efficiency has been proved on several examples but a demonstration proving its generality will be the topic of a coming work.

Let us consider the mechanical system illustrated by Figure 1. The state, input and output vectors are given by: $x=\left[\begin{array}{lllll}p_{1} & p_{2} & p_{3} & q_{1} & q_{2}\end{array}\right]^{T} ; u=\left[\begin{array}{lll}F_{1} & F_{2}\end{array}\right]^{T}$ and $y=\left[\begin{array}{ll}V_{1} & V_{2}\end{array}\right]^{T}$.

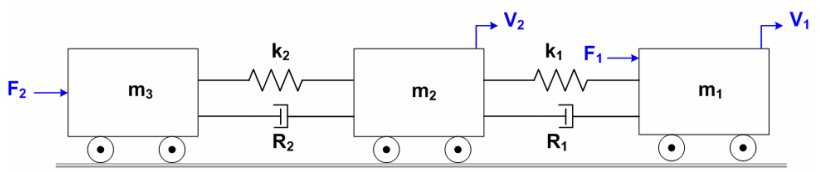

Figure 1: Mechanical system

Let us consider that the shock absorber $R_{2}$ has a negligible effect on the system. The bond graph model in preferential integral causality without considering this element is shown on Figure 2.

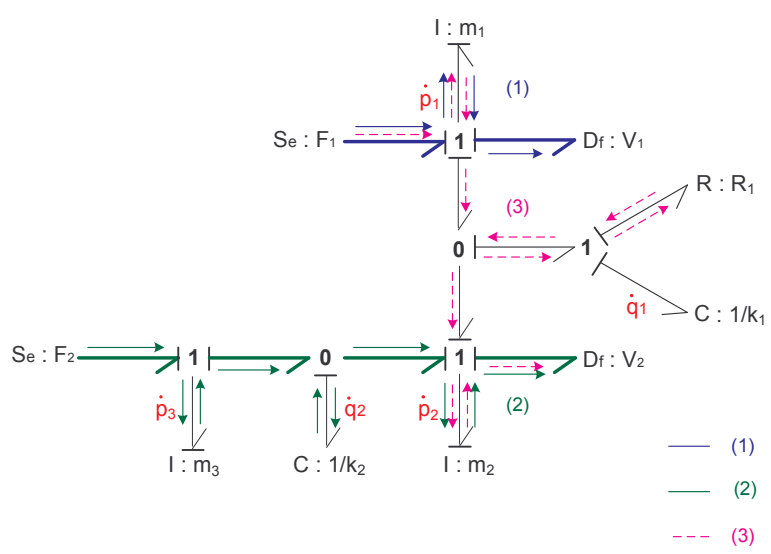

Figure 2: Bond graph model in preferential integral causality

This system has two independent I/O power lines: $\left(\mathrm{F}_{1}\right.$, $\left.V_{1}\right)$ and $\left(F_{2}, V_{2}\right)$, then necessary condition of the invertibility is satisfied. The disjoint $\mathrm{I} / \mathrm{O}$ causal paths are $\left(\mathrm{F}_{1}, \mathrm{~V}_{1}\right)$ : (1) and $\left(\mathrm{F}_{2}, \mathrm{~V}_{2}\right)$ : (2). This lead to $L_{2}=1+3=4$ as length of the disjoint I/O causal paths. The relative degrees of the outputs are $l_{1}=n_{1}^{\prime}=1$; $l_{2}=n_{2}^{\prime}=2$, the essential orders are: $n_{1 e}=L_{2}-l_{2}=2$; $n_{2 e}=L_{2}-l_{1}=3$ and the orders of the infinite zeros are: $n_{1}=L_{1}=1 ; n_{2}=L_{2}-L_{1}=3$.

Let us define the bicausal bond graph model on Figure 3 by replacing each input, respectively each output, by a double detector, respectively a double source, and by propagating the bicausality along the $\mathrm{O} / \mathrm{I}$ power lines. 


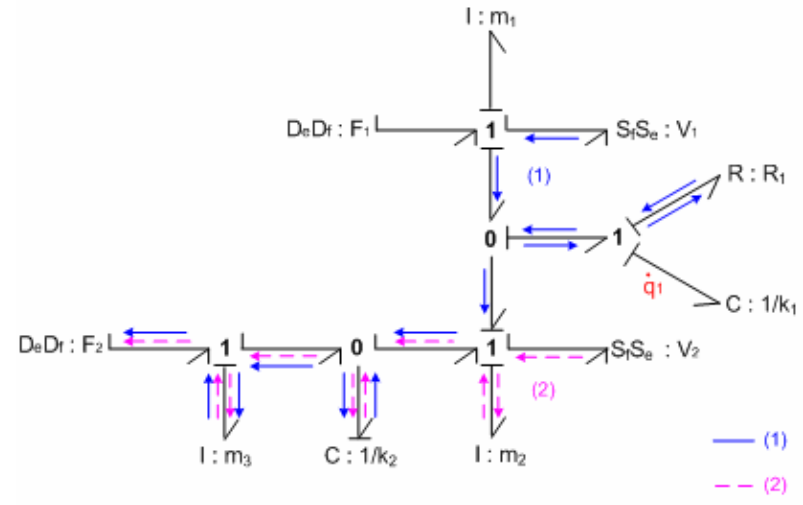

Figure 3: Bicausal bond graph model

The causal path $\left(\mathrm{V}_{1}, \mathrm{~F}_{2}\right)$ : (1) is the causal path of the highest order connecting the output $\mathrm{V}_{1}$ to an input, then $n_{1 e}=O_{h}\left(V_{1}, F_{2}\right)=2$. In the same way, The causal path $\left(\mathrm{V}_{2}, \mathrm{~F}_{2}\right)$ : (2) is the causal path of the highest order connecting the output $\mathrm{V}_{2}$ to an input, then $n_{2 e}=O_{h}\left(V_{2}, F_{2}\right)=3$. Thus, we can conclude that defining the essential orders on the bicausal bond graph model is easier than defining these orders on the bond graph model in preferential integral causality. The inverse model is directly computed from the bicausal bond graph model (Figure 3).

$$
\left\{\begin{array}{l}
\frac{d}{d t}\left(q_{1}\right)=V_{1}-V_{2} \\
F_{1}=m_{1} \frac{d}{d t}\left(V_{1}\right)+R_{1}\left(V_{1}-V_{2}\right)+k_{1} q_{1} \\
F_{2}=\frac{m_{2} m_{3}}{k_{2}} \frac{d^{3}}{d t^{3}}\left(V_{2}\right)+\frac{m_{3} R_{1}}{k_{2}}\left(\frac{d^{2}}{d t^{2}}\left(V_{2}\right)-\frac{d^{2}}{d t^{2}}\left(V_{1}\right)\right) \\
\quad-\frac{m_{3} k_{1}}{k_{2}} \frac{d}{d t}\left(V_{1}\right)+\left(m_{2}+m_{3} \frac{\left(k_{1}+k_{2}\right)}{k_{2}}\right) \frac{d}{d t} V_{2} \\
\quad+R_{1}\left(V_{2}-V_{1}\right)-k_{1} q_{1}
\end{array}\right.
$$

Let us denote by $d_{i} \mathrm{i}=1,2$ the necessary number of derivations of outputs in the inverse model, then $d_{1}=2$ and $d_{2}=3$. We remark that $\left(d_{1}=n_{1 e}\right) \geq n_{1}^{\prime}$ and $\left(d_{2}=n_{2 e}\right) \geq n_{2}^{\prime}$, so the highest derivation order of each output in the inverse model is different from the relative degree. This number corresponds to the essential order $n_{i e}$.

\section{FEEDBACK DECOUPLING ANALYSIS}

In this section, static decoupling conditions will be presented by algebraic and bond graph approaches and the case of dynamic extension will be treated.

Let us recall that the invertibility implies the decoupling of the square linear system (1). Thus, after verifying the system invertibility, we can be interested by feedback decoupling.
The square system $(p \times p)$ defined by the triplet (A, B, C) is decouplable by a static feedback of the form $u=K x+L v$ with $L$ a non-singular matrix if and only if one of these three equivalent conditions is satisfied:

(i) The decoupling matrix $B^{*}$ is non-singular (Falb and Wolovich 1967):

$$
B^{*}=\left(\begin{array}{c}
c_{1} A^{n_{1}^{\prime}-1} B \\
\vdots \\
c_{i} A^{n_{i}^{\prime}-1} B \\
\vdots \\
c_{p} A^{n_{p}^{\prime}-1} B
\end{array}\right)
$$

(ii) (Dion and Commault 1993):

$$
\sum_{i=1}^{p} n_{i}=\sum_{i=1}^{p} n_{i}^{\prime}
$$

(iii) (Commault et al. 1986):

$$
n_{i e}=n_{i}^{\prime} \quad \forall \mathrm{i} \in\{1, \ldots, \mathrm{p}\}
$$

Gilbert (1969) showed that there is a class of invertible systems not decouplable by static feedback but which require a dynamic extension to achieve decoupling by feedback. In this case, the essential order $n_{i e}$ of the $\mathrm{i}^{\text {th }}$ output is strictly superior to its relative degree $n_{i}^{\prime}$.

An invertible system represented by a bond graph model is decouplable by a static feedback if the following equivalent conditions are verified (Rahmani et al. 1996):

$$
\begin{aligned}
& L_{p}=\sum_{i=1}^{p} l_{i} \\
& \left\{n_{i}\right\}=\left\{n_{i}^{\prime}\right\}
\end{aligned}
$$

Then an invertible model is decouplable by a static feedback if the lowest sum of the lengths of the $p \mathrm{I} / \mathrm{O}$ disjoint causal paths is equal to the sum of the lengths of the shortest causal paths between every output $i$ and all the inputs.

\section{Property2}

The bond graph model is decouplable by a static feedback if the following condition is satisfied:

$$
l_{i}=L_{p}-\sum_{j=1, j \neq i}^{p} l_{j} \quad \forall \mathrm{i} \in\{1, \ldots \mathrm{p}\}
$$

If this decoupling condition is not satisfied, it is always possible to find the inverse model. In this case, a natural dynamic extension occurs during the construction of the inverse model. 
Property3

If the system is not statically decouplable then the dynamic extension order is calculated on the model bond graph as follows:

$$
n_{d e}=L_{p}-\sum_{j=1}^{p} l_{j}
$$

Let us study the decouplability of the mechanical system (Figure1). In fact, we remark that $n_{1 e} \neq n_{1}^{\prime}$ and $n_{2 e} \neq n_{2}^{\prime}$, then we can deduce that the system is not decouplable by static feedback. A dynamic compensation is necessary to decouple the model and its order is computed as follows: $n_{d e}=L_{2}-l_{1}-l_{2}=4-1-2=1$.

\section{FEEDBACK DECOUPLING SYNTHESIS}

In this section, a method will be given to synthesize a statically decouplable system by bond graph approach.

Obviously, if a system is not statically decouplable, then a dynamic compensation is necessary. The dynamic compensation consists of adding dynamics in the model. The classic method of dynamic compensation consists on the insertion of additional integrators in order to delay the effect of the fastest entry. This mathematical method enables automatically to increase the model order and is made independently from the physical phenomena of the system. The dynamic extension orders will be used here to determine what phenomena has to be considered or added in the initial model to obtain a new system that is statically decouplable. A new design can be applied to simplify the command without using mathematical methods. The synthesis of the new design is closely linked to the structure and the nature of the system under study. This enables the system to be reviewed and considers the physical phenomena that have been neglected or adds physical phenomena having insignificant effects on the system (e.g. adding a low inductance coil in an electric network and which does not affect the system behaviour). This approach is an aid to design systems statically decouplable (that will be easier to control) and it does not require any calculation.

From the bond graph model, we can deduce a number of informations that will help to analyze the initial system and identify the bond graph structure that make it not statically decouplable. In fact, if the system is not statically decouplable then for one or several outputs there is an I/O causal path shorter than the disjoint $\mathrm{I} / \mathrm{O}$ causal path associated to this output. In order to identify these outputs, the I/O causal paths $\left(u_{j}, y_{i}\right)$ which have served to compute the relative degrees (the shortest I/O causal paths associated to the outputs) must be located. For each output, the length of the shortest path $\left(\mathrm{u}_{\mathrm{j}}, \mathrm{y}_{\mathrm{i}}\right)$ must be compared at the length of the disjoint I/O causal path $\left(u_{k}, y_{i}\right)$ associated to this output; if the length of the $\mathrm{I} / \mathrm{O}$ causal path $\left(\mathrm{u}_{\mathrm{j}}, \mathrm{y}_{\mathrm{i}}\right)$ is the inferior one, then one of this two causal paths must be modified in order to delay the fastest input. According to the modelling hypotheses, the possible modifications of the system consist in the addition or the deletion of a bond graph structure with only one set of junctions, dissipative and dynamic elements in order to increase the length of the shortest I/O causal path or to reduce the length of the disjoint I/O causal path. The order of this modification corresponds to the dynamic extension order (17).

Let us synthesize a decouplable model by a static feedback from the initial model (Figure 2). This model is not decouplable because the $\mathrm{I} / \mathrm{O}$ causal path $\left(\mathrm{F}_{1}, \mathrm{~V}_{2}\right)$ is shorter than the disjoint $\mathrm{I} / \mathrm{O}$ causal path $\left(\mathrm{F}_{2}, \mathrm{~V}_{2}\right)$. So the length of the causal path $\left(\mathrm{F}_{1}, \mathrm{~V}_{2}\right)$ must be increased or the length of the causal path $\left(\mathrm{F}_{2}, \mathrm{~V}_{2}\right)$ must be shortened. The consideration of the shock absorber $\mathrm{R}_{2}$ (that has been neglected in the beginning) in the model renders the causal path $\left(\mathrm{F}_{2}, \mathrm{~V}_{2}\right)$ shorter, then the associated bond graph model in preferential integral causality is defined by Figure 4 and the associated bicausal bond graph model is defined by Figure 5 .

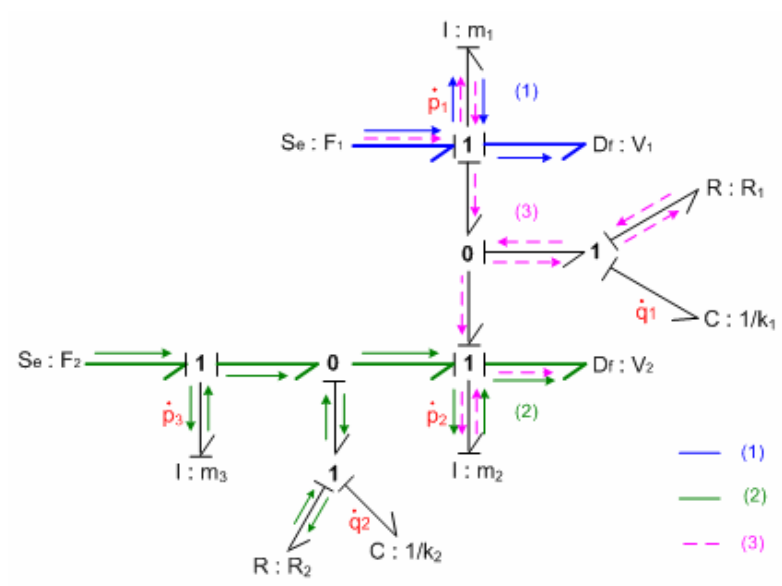

Figure 4: Bond graph model with the consideration of the shock absorber $\mathrm{R}_{2}$

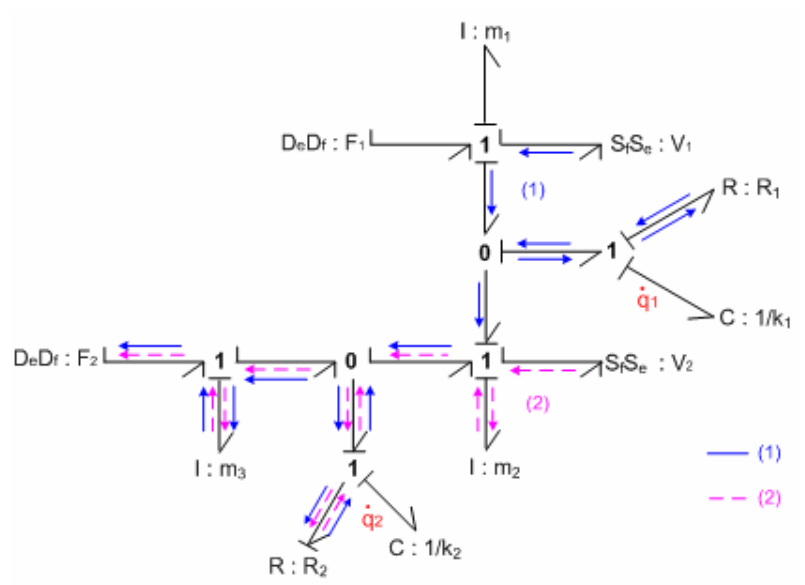

Figure 5: The associated bicausal bond graph model 
The model is still structurally invertible and the unique set of disjoint I/O causal paths is $\left\{\left(\mathrm{F}_{1}, \mathrm{~V}_{1}\right) ;\left(\mathrm{F}_{2}, \mathrm{~V}_{2}\right)\right\}$, its length is then $L_{2}=1+2=3$. The structural properties are: $l_{1}=n_{1}^{\prime}=1 ; l_{2}=n_{2}^{\prime}=2 ; n_{1 e}=1 ; n_{2 e}=2$; $n_{1}=L_{1}=1 ; n_{2}=L_{2}-L_{1}=2$. Note that $n_{1 e}=n_{1}^{\prime}$ and $n_{2 e}=n_{2}^{\prime}$, then the model is decouplable by static feedback.

The inverse model is the following:

$$
\left\{\begin{aligned}
\dot{q}_{1}= & V_{1}-V_{2} \\
\dot{q}_{2}= & \frac{m_{2}}{R_{2}} \dot{V}_{2}+\frac{R_{1}}{R_{2}}\left(V_{2}-V_{1}\right)-\frac{k_{1}}{R_{2}} q_{1}-\frac{k_{2}}{R_{2}} q_{2} \\
F_{1}= & m_{1} \dot{V}_{1}+R_{1}\left(V_{1}-V_{2}\right)+k_{1} q_{1} \\
F_{2}= & \frac{m_{2} m_{3}}{R_{2}} \ddot{V}_{2}+\left(m_{2}+m_{3}+\frac{m_{3} R_{1}}{R_{2}}-\frac{m_{2} m_{3} k_{2}}{R_{2}^{2}}\right) \dot{V}_{2} \\
& -\frac{m_{3} R_{1}}{R_{2}} \dot{V}_{1}+\left(R_{1}+\frac{m_{3} k_{1}}{R_{2}}-\frac{m_{3} R_{1} k_{2}}{R_{2}^{2}}\right)\left(V_{2}-V_{1}\right) \\
& +\left(\frac{m_{3} k_{1} k_{2}}{R_{2}^{2}}-k_{1}\right) q_{1}-\frac{m_{3} k_{2}^{2}}{R_{2}^{2}} q_{2}
\end{aligned}\right.
$$

The highest derivation order of each output corresponds now to the relative degree. The model order has not been increased. In fact, it was enough to consider a simple dissipative element to decouple the model.

It shows that modifying the modelling hypotheses may be a possible way to change the structural properties of the system and enables the static decoupling of the system (It is the case of the shock absorber $R_{2}$ in the proposed example).

\section{CONCLUSION}

It has been shown that the essential orders of each output system can be graphically obtained from the bond graph model. This approach enables to deduce, directly after the bond graph modelling, relevant information on the design and the control of the system.

A new condition for decoupling by static feedback (using essential orders) has been defined on the bond graph model. The decoupling by dynamic extension was discussed. The dynamic extension order can be directly deduced from the bond graph model. Finally, an approach enabling the synthesis a model statically decouplable has been defined. This approach is linked to the structure and the behaviour of the system; It enables the system reviewing: Analyze all the neglected physical phenomena and add others elements to the system if it is necessary. The contribution of this approach appears at the design step where it is easy to modify the model and consequently the system in order to define an adequate structure to the command requirements.

\section{REFERENCES}

Bertrand, J.M.; C. Sueur and G. Dauphin-Tanguy. 1997. "On the finite and infinite structures of bond graph models." Proceedings of the 1997 IEEE International Conference on Systems Man and Cybernetics (Orlando USA, Oct), vol.3, 2472-2477.

Bideaux, E.; J. Laffite; A. Derkaoui; W. Marquis-Favre; S. Scavarda and F. Guillemard. 2006. "Design of a Hybrid Vehicle Powertrain using an Inverse Methodology." Journal Européen des Systèmes Automatisés, vol.40, pp.279-290.

Commault, C.; J. Descusse; J.M. Dion; J.F. Lafay and M. Malabre. 1986. "New decoupling invariants: the essential orders." International Journal of Control, vol.44, No.3, 689-700.

Cremer, M. 1971. "A precompensator of minimal order for decoupling a linear multivariable system." International Journal of Control, vol.14, No.6, 1089-1103.

Dauphin-Tanguy, G.; A. Rahmani and C. Sueur. 1999. "Bond graph aided design of controlled systems." Simulation Practice and Theory, vol.7, No.5-6, 493-512.

Dauphin-Tanguy, G. et al. 2000. Les bond graphs, 383p, Hermes Science, Paris.

Dion, J.M. and C. Commault.1993. "Feedback decoupling of structured systems." IEEE Transactions on Automatic Control, vol.38, No.7, 1132-1135.

Falb, P.L. and W.A. Wolovich. 1967. "Decoupling in the Design and Synthesis of Multivariable Control Systems." IEEE Transactions on Automatic Control, vol.AC-12, No.6, 651-659.

Gawthrop, P.J. 1995. "Bicausal bond graphs." Proceedings of International Conference on Bond Graph Modelling and Simulation: ICGBM'95(Las Vegas), 83-88.

Gawthrop, P.J. 1997. "Control system configuration: Inversion and bicausal bond graphs." Proceedings of International Conference on Bond Graph Modelling and Simulation: ICGBM'97( Phoenix), 97-102.

Gawthrop, P.J. 2000. "Physical Interpretation of Inverse Dynamics Using Bicausal Bond Graphs." Journal of the Franklin Institute, vol.337, 743-769.

Gawthrop, P.J; and G.P. Bevan. 2007. "Bond graph modeling." IEEE Control Systems Magazine, vol.27, 2445.

Gilbert, E.G. 1969. "Decoupling of multivariable systems by state feedback." S.I.A.M. Journal of Control, vol.7, No.1, pp50-63.

Junco, S.; C. Sueur and G. Dauphin-Tanguy. 2005. "Nonlinear control of a series direct current motor via flatness and decomposition in the bond graph domain." Proceedings of the Institution of Mechanical Engineers, Part I: Journal of Systems and Control Engineering, vol.219, No.3, 215-230.

Karim, A.; C. Sueur and G.Dauphin-Tanguy.2003. "Nonregular static state feedback for linear bond graph models." Proceedings of the Institution of Mechanical Engineers, Part I: Journal of Systems and Control Engineering, vol.217, No.2, 61-71.

Karnopp, D. C.; D. L. Margolis and R.C. Rosenberg. 1990. "System Dynamics: A Unified Approach." Ed. John Wiley, New York.

Karnopp, D.C.; D.L. Margolis and R.C. Rosenberg. 2000. "System dynamics: modeling and simulation of mechatronic systems." 507p., John Wiley and sons, NewYork. 
Loiseau, J.J. 1986. "Sur la modification de la structure à l'infini par retour d'état statique."PhD thesis, Nantes University.

Margolis, D.L. 1984. "Bond graphs for vehicle stability analysis." International Journal of Vehicle Design, vol.5, No.4, 427-437.

Ngwompo, R.F. 1997. "Contribution au dimensionnement des systèmes sur des critères dynamiques et énergétiques : approche bond graph." $\mathrm{PhD}$ Thesis, Labiratory : Automatique Industrielle, Institut National des Sciences Appliquées, Lyon-France, 216p.

Ngwompo, R.; S. Scavarda and D. Thomasset. 1999. "Inversion of linear time invariant SISO systems modeled by bond graph." Journal of the Franklin Institute, vol.333B, No.2, 157-174.

Ngwompo, R.F.; S. Scavarda and D. Thomasset. 2001. "Physical model-based inversion in control systems design using bond graph representation, Part 1: theory." Proceedings of the Institution of Mechanical Engineers. Part I: Journal of Systems and Control Engineering, vol.215, No.2, 95-103.

Ngwompo, R.F.; E. Bideaux and S. Scavarda. 2005. "On the role of power lines and causal paths in bond graph based model inversion." Proceedings of International Conference on Bond Graph Modelling and Simulation: ICGBM'05, vol.37(1), 5-10.

Rahmani, A.; C. Sueur and G. Dauphin-Tanguy. 1992. "Formal determination of controllability/observability matrices for multivariable systems modelled by bond graph." Proceeding of IMACS/SICE Int. Symposium of Robotics, Machatronics and Manufacturing System'92, 573-580.

Rahmani, A.; C. Sueur and G. Dauphin-Tanguy .1996. "On the infinite structure of systems modelling by bond graph: feedback decoupling." Proceedings of the 1996 IEEE International Conference on Systems Man and Cybernetics(Beijing China,Oct), vol.3, 1617-1622.

Rosenberg, R.C; M.K. Hales and M.A. Minor. 1996. "Engineering icons for multidisciplinary systems." American Society of Mechanical Engineers Dynamic Systems and Control Division (New-York, Nov), vol.98, 665-672.

Sueur, C. and G. Dauphin-Tanguy. 1989. "Structural controllability/observability of linear systems represented by bond graphs." Journal of the Franklin Institute., vol.326, No.6, pp869-883.

Sueur, C. and G. Dauphin-Tanguy. 1991. "Bond graph approach for structural analysis of MIMO linear systems." Journal of the Franklin Institute, vol.328, No.1, 55-70.

Van Dijk, J. 1994. "On the role of bond graph causality in modelling mechatronic systems." PhD thesis, Dept of Electrical engineering: University of Twente, Enschede, Netherlands, 220p.

Wu, S.-T. and K. Youcef-Toumi. 1995. "On the relative degrees and zero dynamics from physical system modelling." Journal of Dynamic Systems, Measurement and Control Transactions of the American Society of Mechanical Engineers "ASME" (New-York USA), vol.117, No.2, 205-217.

\section{AUTHOR BIOGRAPHIES}

MARIEM EL FEKI was born in Ariana, Tunisia and went to the National Institute of Applied Sciences and Technology (Tunis, Tunisia). She obtained engineering diploma in industrial data processing and automatic
(2007). In the same year, she obtained the Master of Research degree in automation system engineering from National Institute of Applied Sciences, Lyon (France) .She is now a Ph.D. student at "Ecole Centrale de Lyon" (France) and her research interests include structural analysis and sizing of Mecatronics systems by bond graph approach. Her e-mail address is: mariem.el-feki@ec-lyon.fr

MICHAEL DI LORETO received the M.S. degree from Ecole Centrale de Nantes, Nantes, France, in 2003, in automatic and computer engineering. He received the Ph.D. degree in automatic control from Ecole Centrale de Nantes, Nantes, France, in 2006. From 2006, he joined the INSA Lyon and Laboratoire Ampere, Lyon, France, where he is actually associated professor. His research interests include linear and nonlinear control theory, infinite dimensional systems, with particular emphasis in structural analysis. His e-mail address is: michael.di-loretoeinsa-lyon.fr

ERIC BIDEAUX obtained his Engineering degree in Mechanics in 1991 (Nantes, France) and his Ph.D. degree in Control and Industrial Automation in 1995 from Franche-comté University (France). He joined The National Institute of Applied Sciences (Lyon, France) and Ampere Laboratory in 1996. He is Professor since 2006 and his research interests include modelisation, fluid power, control and sizing of mecatronics systems. His e-mail address is: eric.bideaux@insa-lyon.fr

DANIEL THOMASSET, Engineer (1972) in Electrical Engineering (option Control), PhD (1978) and "Doctorat d'Etat français" (1987). He is currently Professor at the National Institute of Applied Sciences, Lyon, France. His research interests include control and sizing of Mecatronics systems especially Fluid Power systems. He obtain (2001), with R. Fotsu Ngwompo and S. Scavarda, the Donald Julius Price of the Institution of Mechanical Engineers, U. K., for their work on sizing described in the paper "Physical model-based inversion in control systems design using Bond Graph representation", Proceedings of ImechE, Part I: Journal of Systems and Control Engineering, vol 15, $\mathrm{n}^{\circ} 12$, 2001. His e-mail address is: daniel.thomasseteinsa-lyon.fr

WILFRID MARQUIS-FAVRE is Assistant Professor in the Laboratory Ampère since 1998. He obtained his Engineering degree in Mechanics in 1992, his Master of Research degree in Industrial Automation in 1994, and his $\mathrm{Ph}$. D. degree in Industrial Automation in 1997 in the Laboratory of Industrial Automation at the National Institute of Applied Sciences of Lyon (France). His main areas of research are modelling, simulation, analysis and design of mechatronic systems; inversion and optimization in bond graph language for the system sizing. His e-mail address is: wilfrid.marquisfavredinsa-lyon.fr 